Elsevier required licence: (C) <2019>. This manuscript version is made available under the CC-BY-NCND 4.0 license http://creativecommons.org/licenses/by-nc-nd/4.0/

The definitive publisher version is available online at

[https://www.sciencedirect.com/science/article/pii/S1871519219301416?via\%3Dihub] 


\title{
Induction of labour indications and timing: A systematic
}

\author{
analysis of clinical guidelines
}

\begin{abstract}
Background: There is widespread and some unexplained variation in induction of labour rates between hospitals. Some practice variation may stem from variability in clinical guidelines. This review aimed to identify to what extent induction of labour guidelines provide consistent recommendations in relation to reasons for, and timing of, induction of labour and ascertain whether inconsistencies can be explained by variability guideline quality.
\end{abstract}

Method: We conducted a systematic search of national and international English-language guidelines published between 2008 and 2018. General induction of labour guidelines and conditionspecific guidelines containing induction of labour recommendations were searched. Guidelines were reviewed and extracted independently by two reviewers. Guideline quality was assessed using the Appraisal of Guidelines for Research and Evaluation II Instrument.

Findings: 49 guidelines of varying quality were included. Indications where guidelines had mostly consistent advice included prolonged pregnancy (induction between 41 and 42 weeks), preterm premature rupture of membranes, and term preeclampsia (induction when preeclampsia diagnosed $\geq 37$ weeks). Guidelines were also consistent in agreeing on decreased fetal movements and 
oligohydramnios as valid indications for induction, although timing recommendations were absent or inconsistent. Common indications where there was little consensus on validity and/or timing of induction included gestational diabetes, fetal macrosomia, elevated maternal body mass index, and twin pregnancy.

Conclusion: Substantial variation in clinical practice guidelines for indications for induction exists. As guidelines rated of similar quality presented conflicting recommendations, guideline variability was not explained by guideline quality. Guideline variability may partly account for unexplained variation in induction of labour rates.

Keywords: clinical guidelines, guideline review, AGREE II, induction of labour, clinical variation

\section{Statement of Significance}

\section{Problem}

There is significant unexplained variation in induction of labour rates between hospitals.

\section{What is Already Known}

Variation cannot be adequately explained by differences in women's demographics, comorbidities, or hospital factors. The causes of variation in induction of labour rates remain unknown but it has been suggested that variation may stem from inconsistencies in clinical guidelines.

\section{What this Paper Adds}

This study shows that there is substantial variation in clinical practice guidelines for common indications for induction, which cannot be explained by guideline quality. Guideline variability appears to reflect differing, subjective interpretations of often sparse underlying evidence. 


\section{Background}

There has been a considerable rise in women having induction of labour (IOL) over recent decades in high income countries ${ }^{1-4}$. In Australia, with around 300,000 births per year, the IOL rate increased from $25 \%$ in 2006 to $31 \%$ in $2016{ }^{5}$. This increase of $6 \%$ means that in 2016 a total of 18,615 more women had an IOL than in $2006^{6}$. Labour can be induced using a range of methods, most commonly using vaginal prostaglandins or cervical catheter if the woman's cervix is not favourable, followed by artificial rupture of membranes (ARM) and oxytocin (or ARM \pm oxytocin only if the cervix is favourable $)^{7}$.

$\mathrm{IOL}$ is associated with premature births ${ }^{8}$, decreased maternal satisfaction and a potential intervention cascade ${ }^{2,9}$. Despite these issues, IOL rates continue to increase in high income countries, and there is widespread variation in $\mathrm{OOL}$ incidence between hospitals, even after adjusting for case mix or hospital factors ${ }^{4,10,11}$. Evidence from Australia indicates that IOL rates range from $9.7 \%$ to $41.2 \%$ between hospitals ${ }^{11}$, and that $44 \%$ of hospitals have an adjusted IOL rate that significantly differs from the state average ${ }^{10}$. Similar findings are reported from Europe ${ }^{12}$ and the US

${ }^{13}$. This variations cannot be adequately explained by differences in women's demographics, comorbidities, or hospital factors ${ }^{4,10,11}$, and this requires further investigation.

Unexplained variation in rates of intervention raises doubt about the appropriateness of the intervention ${ }^{14,15}$. It also suggests different practice styles and variability in the extent to which evidence-based clinical guidelines are followed ${ }^{16-19}$. Furthermore, it is possible that practice variation stems from inconsistencies in clinical guidelines despite using the same evidence-base ${ }^{18,20}$. Guidelines developed by different groups addressing the same clinical issue can result in conflicting 
recommendations ${ }^{21}$, and vary in quality ${ }^{22}$, making it hard for clinicians to provide consistent care and difficult for women to know what is likely to be best for them.

To help make sense of variations in the incidence and timing of IOL, we conducted a review of IOL guidelines for areas of divergence and convergence. We compared recommendations in relation to the timing and indications for IOL and assessed the quality of guidelines using the Appraisal of Guidelines for Research and Evaluation (AGREE II) Instrument ${ }^{23}$. The aim of this review was to (a) identify the extent to which IOL guidelines provide consistent recommendations in relation to reasons for, and timing of, planned birth, and (b) ascertain whether inconsistencies can be explained by variability in the quality of guidelines.

\section{Method}

\section{Search strategy and guideline eligibility}

We conducted a systematic search to identify guidelines in relation to indications for IOL published in English between January $1^{\text {st }} 2008$ and December 31st 2018. International and Australian guidelines were included, as well as guidelines from countries considered similar to Australia in terms of their availability and delivery of healthcare, namely New Zealand (NZ), the United States (US), the United Kingdom (UK), Ireland and Canada. Guidelines from national and state government and professional bodies were included; guidelines developed at local health district (LHD) or hospital level were excluded unless they are the guidelines used across the state (e.g. King Edward Memorial Hospital in Perth often provides the guidance for the whole of the state of Western Australia). All international guidelines were considered providing they were written in English ( 2 identified for inclusion ${ }^{24,25}$ ). 
We used a number of search strategies to identify guidelines. As other guidelines reviews have found that guidelines are best sourced by a systematic grey literature search ${ }^{20,26}$, in the first instance, we searched the internet using the search terms 'induction of labo(u)r' and 'guideline' and the individual indications for IOL in combination with 'guideline'. The indications searched for included prolonged pregnancy; premature rupture of membranes; uncomplicated twin pregnancy; breech presentation; cholestasis of pregnancy; antepartum haemorrhage; chorioamnionitis; hypertension, preeclampsia; gestational or Type I or II diabetes; elevated maternal body mass index; maternal age; maternal ethnicity; maternal cardiac disease; maternal request; mental health reason; previous adverse perinatal outcome; history of precipitate labour; fetal macrosomia; fetal growth restriction; decreased fetal movements; oligohydramnios; fetal isoimmunisation/alloimmune disease or Rhesus disease; and fetal death).

Guidelines were also purposively sought from key national authorities in relation to obstetrics and maternity care in each of the six countries, specifically: Australian Health Departments; Australian National Health and Medical Research Council (NHMRC); New Zealand Guidelines Group (NZGG); Royal Australian and New Zealand College of Obstetricians and Gynaecologists (RANZCOG); Royal College of Obstetricians and Gynaecologists (RCOG), United Kingdom; National Institute of Clinical Excellence (NICE), United Kingdom; The Scottish Intercollegiate Guidelines Network (SIGN); Institute of Obstetricians and Gynaecologists, Royal College of Physicians of Ireland; the Society of Obstetricians and Gynaecologists of Canada (SOGC); and World Health Organization (WHO), Geneva. Guidelines from national bodies that could not be accessed without member access were excluded (e.g. Women's Hospitals Australasia). This initial search strategy identified 59 guidelines for full review, of which 46 were included (see Figure 1). 
To cross check that our search strategy was comprehensive, we also searched the electronic database PubMed, using the terms 'induction of labo(u)r' or 'labo(u)r induction' in combination with 'guideline'. This search generated 2401 articles for screening, but only identified two further guidelines for inclusion. Lastly, we searched the International Guideline Library using the terms 'induction' and 'induction of labo(u)r' and this search identified one further guideline for inclusion.

\section{Insert Figure 1}

All guidelines that addressed IOL in relation to indications and/or timing were included. Guidelines devoted specifically to IOL and general guidelines in relation to maternity care were also included, providing the guideline included a recommendation in relation to indications or timing of IOL.

\section{Data extraction and quality appraisal}

The guidelines were independently reviewed by two reviewers. Recommendations in relation to the reasons for, and timing of, IOL were extracted using a purposely designed data extraction template. Recommendations in relation to the possible IOL indications were systematically extracted. The quality of each guideline was assessed using the Appraisal of Guidelines for Research and Evaluation (AGREE II) Instrument ${ }^{23}$. The AGREE II Instrument is a valid and reliable tool for assessing the quality of guidelines, which evaluates six domains: scope and purpose; stakeholder involvement; rigour of development; clarity and presentation; applicability; and editorial independence. The instrument has been endorsed by the World Health Organization and is widely accepted as the gold standard for the development of quality clinical guidelines ${ }^{27}$. Two assessors independently appraised each guideline, with a third reviewer to resolve discrepancies (which was not required). 
In the first instance, appraisers' scores for each of the six domains were entered into a spreadsheet, and calculated as a percentage. Discrepancies of greater than $30 \%$ were discussed at a consensus meeting and resolved, until the difference between the score was less than $30 \%$ (required for five guidelines). The final score was calculated by averaging the scores. As each of the six domains evaluates discrete aspects of the guideline quality, the six domains are considered independently and were not aggregated into a single quality score. The guidelines were also given an overall assessment score of between 1 and 7 . In terms of the use of the guideline in practice, following the approach used in similar studies ${ }^{28}$ a guideline was labelled as 'strongly recommended' if most domain scores (at least four of six) were greater than 60\%. Guidelines were 'recommended with provisions or alterations' if most domain scores were between 30 and $60 \%$, or at least two domain scores were no less than $60 \%$. This label was also given to guidelines that had insufficient or lacking information for some items; however, if provisions or alterations were performed, then the guidelines were still considered for use in practice, especially when no other guidelines on the same clinical topic were available. A guideline was labelled as 'not recommended' if most of the domain scores were less than $30 \%$.

\section{Results}

We identified 49 guidelines for inclusion (Table i), assessed as of varying quality (Table ii).

Twenty four guidelines were from Australia ${ }^{29-52}, 12$ from the UK ${ }^{7,53-63}$, eight from Ireland ${ }^{64-71}$, one from the US ${ }^{72}$, one from Canada ${ }^{73}$, one from New Zealand ${ }^{74}$ and two international guidelines ${ }^{24,25}$. The Australian guidelines included two national guidelines ${ }^{31,32}$, nine from Western Australia ${ }^{33-41}$, six from Queensland ${ }^{42-47}$, three from South Australia ${ }^{48-50}$, two from New South Wales ${ }^{29,30}$, one from the Australian Capital Territory ${ }^{51}$ and one from Victoria ${ }^{52}$. 
A total of 38 guidelines regarded specific indications for IOL, nine regarded IOL generally, and two regarded maternity care more broadly (but included recommendations in relation to indication or timing of $(\mathrm{OL})$. Indications covered by the guidelines are outlined in Figure 1.

Insert Table i

Insert Table ii

\section{Pregnancy indications}

\section{Prolonged pregnancy}

With the exception of one guideline that did not address timing ${ }^{72}$, these guidelines consistently recommend IOL between 41 and 42 weeks gestation $7,24,30,31,35,42,48,51,52,57,73,74$. While most guidelines state that IOL is indicated when women are 'between $41+0$ and $42+0$ weeks', two guidelines are more specific and recommend IOL by $41+5$ weeks $^{74}$ or by no later than $41+3$ weeks ${ }^{35}$. Seven guidelines emphasised that IOL timing should be informed by women's preferences and a process of shared decision-making $7,30,31,42,51,52,57$. Four of these further stipulated that if a woman chooses not to have IOL that her decision should be respected $7,30,52,57$. There is some variation in the guidelines in terms of when increased fetal monitoring for women with prolonged pregnancy should commence, ranging from $41+0$ weeks ${ }^{30,35}, 41+3$ weeks ${ }^{52}$, to 42 weeks ${ }^{57}$.

\section{Premature Rupture of Membranes}

Premature Rupture of Membranes (PROM) - at term (at or over 37 weeks)

Guidelines present conflicting recommendations in relation to PROM at term. While some guidelines state that IOL is indicated (as soon as possible or within 24 hours) ${ }^{24,36,52,72,73}$, other guidelines state 
that women should be offered a choice of IOL or expectant management ${ }^{7,45,74}$. Some guidelines differentiate between women with PROM at term who are positive for group B streptococcus versus those who are negative. These indicate that women who are positive should receive an IOL with greater urgency than those who are not, and should be induced 'as soon as possible' ${ }^{45,52}$, within 24 hours ${ }^{73}$, or within 6 hours $^{36}$.

\section{Premature Rupture of Membranes - Preterm (<37 weeks)}

Recommendations in terms of the management of preterm PROM is consistent across guidelines. All relevant guidelines state that IOL should not be carried out before 34 weeks unless there are additional obstetric indications such as suspected fetal compromise, and that women with preterm PROM after 34 weeks can be offered IOL or managed expectantly, depending on the risks and benefits for the woman and baby 7,49,52,59,67.

\section{Twin pregnancy}

The relevant guidelines recommend planned birth for women with an uncomplicated twin pregnancy (i.e. first twin cephalic) $42,51,66,73$, with slightly varying recommendations around timing. Some guidelines recommend IOL at $\geq 37$ weeks ${ }^{42}$, at $\geq 38$ weeks $^{73}$, or between 37 and 38 weeks ${ }^{74}$ without differentiating between monochorionic or dichorionic pregnancies. Guidelines that differentiate between monochorionic or dichorionic pregnancies, recommend IOL for monochorionic pregnancies at $36+0^{51,55}$ or $37+0$ weeks ${ }^{66}$, and for dichorionic pregnancies at $37+0^{51,55}$ or $38+0$ weeks ${ }^{66}$. The WHO (2011) guideline does not provide a recommendation, stating that there is insufficient evidence to issue a recommendation on $\mathrm{IOL}$ in women with an uncomplicated twin pregnancy at or near term ${ }^{24}$. 


\section{Breech presentation}

Those guidelines that mention IOL for breech presentations, indicate that IOL is not recommended, $7,52,63,71$. Two guidelines indicate that if a woman wishes to have a vaginal breech birth and planned birth is indicated, IOL can be offered after discussing the associated risks 7,52 .

\section{Cholestasis of pregnancy}

Cholestasis of pregnancy is listed as possible indication for $\mathrm{IOL} \geq 37$ weeks depending on individual circumstances $33,42,51,60$, with slightly different recommendations around timing. Most guidelines state that IOL can be offered from 37 weeks, and earlier (at 36 weeks) for severe cases ${ }^{33,42,51}$. The RCOG (2011) guideline is more tentative in its recommendation and indicates IOL should be offered after 37+0 weeks depending on the severity and the circumstances and preferences of the woman 60.

\section{Antepartum haemorrhage}

Antepartum haemorrhage is identified as an indication for IOL by three guidelines. Two guidelines list this as an indication without providing additional information ${ }^{52,73}$. The RCOG (2011) guideline indicates that IOL may or may not be indicated depending on severity and whether the antepartum haemorrhage is associated with maternal and/or fetal compromise ${ }^{61}$. This guideline states that the optimum timing of birth of women presenting with unexplained antepartum haemorrhage and no associated maternal and/or fetal compromise is not established ${ }^{61}$.

\section{Chorioamnionitis}

Three guidelines list chorioamnionitis as an indication for $\mathrm{IOL}^{45,72,73}$, without providing additional information. 


\section{Maternal Indications}

\section{Hypertension and preeclampsia}

All of the guidelines that address IOL for women with hypertension or preeclampsia recommend IOL, with slightly different recommendations around the timing of planned birth $25,29,34,43,48,52,54,68,69,72-74$. In terms of chronic hypertension, most guidelines recommend IOL from 37 weeks ${ }^{43,54,74}$, while one guideline suggests waiting until $38+0$ to $39+6$ weeks, providing the woman is 'otherwise well' ${ }^{69}$. Regarding gestational hypertension, some guidelines recommend IOL from 37 weeks ${ }^{29,54,69}$ while others recommend waiting until between 38 and 39 weeks ${ }^{25,73}$. One guideline states that women with hypertension (without preeclampsia) can be offered the choice of IOL from 37 weeks or expectant management ${ }^{74}$.

For preeclampsia, there is consistency across a number of guidelines that women with onset of preeclampsia at $\geq 37$ weeks should be offered IOL ${ }^{25,34,43,54,72-74}$. Recommendations in terms of the timing of IOL for women with pre-term ( $<37$ weeks) preeclampsia vary, in particular for the management of preeclampsia with mild to moderate hypertension. Some guidelines recommend IOL for women with preeclampsia with mild to moderate hypertension to be delayed until 37 weeks ${ }^{25}$, while others recommend IOL from 34 weeks ${ }^{54,68}$.

Only two guidelines stipulate the need to consider women's needs and preferences in decisionmaking around timing of $\mathrm{IOL}$ for hypertensive disorders ${ }^{54,74}$.

\section{Maternal Diabetes}

\section{Gestational Diabetes}

In relation to gestational diabetes, the guidelines present inconsistent recommendations in terms of whether this is an indication for $\mathrm{IOL}$, in particular in relation to gestational diabetes with no maternal 
or fetal complications. While some guidelines state that, in the absence of other indications, IOL is not indicated (before 42 weeks) ${ }^{46,56}$, others indicate that IOL can be offered from 40 weeks ${ }^{74}, 40+6$ weeks ${ }^{56}$, or 41 weeks ${ }^{24}$. Those guidelines that address gestational diabetes with maternal or fetal complications (e.g. suspected macrosomia or women who require insulin) agree that IOL between 38 and 39 weeks may be required ${ }^{41,46,56}$. A number of guidelines identify gestational diabetes as an indication for IOL, without commentary around the timing that this should occur ${ }^{48}$, or stating more broadly that timing depends on individual risks and preferences and local circumstances ${ }^{42,51,52}$.

\section{Type I or type II Diabetes}

Three guidelines state that IOL is indicated for type I and type II diabetes ${ }^{56,72,73}$, with only one of these providing guidance around timing. This guideline recommends IOL for women with type I or type II diabetes between 37 and 38 weeks, and earlier if there are metabolic or other maternal or fetal complications ${ }^{56}$. Only one of the included guidelines stipulates the importance of shared decision-making with women in decision around timing of $\mathrm{IOL}$ for diabetes ${ }^{46}$.

\section{Other maternal indications}

\section{Elevated Maternal Body Mass Index (BMI)}

In terms of elevated maternal BMI, out of four guidelines, two stipulate BMI as not an acceptable indication for $\mathrm{IOL}$ in the absence of other indications ${ }^{37,65}$. One guideline recommends planned birth at 38 and 39 weeks for all women with a BMI $\geq 50$, and the option for all women who are "above their healthy weight range" to have an $\mathrm{IOL}^{52}$. A fourth guideline states that while, in the absence of other obstetric or medical indications, obesity alone is not an indication for planned birth, a low threshold for IOL at term may be appropriate ${ }^{44}$. 


\section{Maternal age}

In terms of maternal age, guidelines present conflicting recommendations. Most guidelines indicate that women $\geq 40$ years of age may be offered an $\mathrm{IOL}^{42,51,62,73,74}$, while one guideline states that maternal age alone is not an acceptable indication for $\mathrm{IOL}^{52}$. The guidelines that recommend $\mathrm{IOL}$ suggest that occurs at different gestations. This includes recommendations for IOL at 39 weeks ${ }^{73}$, at between 39 and 40 weeks $^{42,51,62}$, or at 40 weeks $^{74}$.

\section{Maternal ethnicity}

Three guidelines comment on maternal ethnicity as an indication for IOL, consistently stating that IOL at term for maternal ethnicity alone is not acceptable ${ }^{42,51,52}$.

\section{Maternal Cardiac Disease}

Two guidelines comment on IOL for women with heart disease, and both indicate that if a planned birth is required, IOL is preferred over caesarean section (CS), but where possible women should be allowed to labour spontaneously ${ }^{39,50}$.

\section{Maternal request}

In relation to maternal request, one guideline identifies this as an unacceptable indication for $1 O L^{73}$, and the other guidelines state that while IOL should not be routinely offered for maternal request, it can be offered under exceptional circumstances (undefined) ${ }^{7,42,51,52}$, after 39 weeks ${ }^{52}$. One example given of an exceptional circumstance is if the woman's partner is soon to be posted abroad with the armed forces ${ }^{7}$.

\section{Mental health reason}

One guideline addresses maternal mental health as a reason for IOL, stating that IOL may be indicated for mental health reasons depending on the woman's circumstances ${ }^{52}$. 


\section{Previous adverse perinatal outcome}

Only one guideline addresses whether a woman's previous adverse perinatal outcome is an indication for IOL, in this instance a previous intrauterine death, stating that this may be an appropriate indication for IOL to alleviate parental anxiety ${ }^{73}$.

\section{History of precipitate labour}

In relation to women having a history of precipitate labour, one guideline identifies this as an acceptable indication for $\mathrm{IOL}^{73}$, while two guidelines indicate this not an appropriate indication ${ }^{7,52}$.

\section{Fetal indications}

\section{Suspected macrosomia}

In relation to suspected macrosomia, guidelines consistently state that this is not an acceptable indication for IOL in the absence of other indications $7,24,42,51,52,73$. Three of these guidelines do recommend IOL in cases of 'confirmed' macrosomia ${ }^{24,42,51}$, with two of these recommending that an ultrasound for estimated fetal weight is conducted when macrosomia is suspected ${ }^{42,51}$. These guidelines recommend that $\mathrm{IOL}$ is offered at $38+0$ weeks if weight is estimated at $3500 \mathrm{~g}$ at approximately 36 weeks, $3700 \mathrm{~g}$ at approximately 37 weeks or $3900 \mathrm{~g}$ at approximately 38 weeks $42,51$.

\section{Suspected fetal compromise}

Suspected fetal compromise may arise with suspected fetal growth restriction, reduced fetal movements, oligohydramnios or fetal alloimmune disease or Rhesus disease. 


\section{Suspected fetal growth restriction}

In relation to suspected fetal growth restriction, the majority of guidelines indicate that planned early birth is appropriate depending on the severity $42,48,51,52,70,72,73$. The exact timing and mode of birth should be informed by the severity of the concern and results of a fetal test of wellbeing 7,42,51,74. Three guidelines recommend delaying IOL until 40+0 weeks, with appropriate monitoring ${ }^{42,51,74}$, provided there are normal middle cerebral artery and uterine Doppler studies ${ }^{74}$. If these studies have not been performed, one guideline recommends IOL around 38 weeks ${ }^{74}$. Another guideline recommends IOL is offered for suspected fetal growth restriction from $37+0$ weeks, or earlier if indicated (i.e. static growth over 3-4 weeks and MCA Doppler $\mathrm{PI}<5$ th centile) ${ }^{38}$. The NICE (2008) guideline states that if there is severe fetal growth restriction with confirmed fetal compromise, CS is preferred ${ }^{7}$.

\section{Decreased fetal movements}

In relation to decreased fetal movements, all guidelines indicate that this may be an appropriate indication for a woman's IOL, depending on clinical circumstances $32,40,42,51,52,74$. The timing should be informed by results of tests for fetal wellbeing, and increased fetal surveillance may be required with expectant management ${ }^{32,42,51}$. Only one guideline offers a recommended timing of $>38$ weeks or earlier if indicated ${ }^{40}$.

\section{Oligohydramnios}

In relation to oligohydramnios, all guidelines indicate that this is an appropriate indication for IOL, depending on clinical circumstances ${ }^{42,48,51,53,72-74}$. The timing of birth depends on the severity of concern and results of tests of fetal wellbeing ${ }^{42,51,53}$, but may be offered between $37-38$ weeks ${ }^{53}$. Increased fetal surveillance is required if expectant management is chosen ${ }^{42,51,53}$. 


\section{Alloimmune disease/Isoimmunisation or Rhesus disease}

Five guidelines list alloimmune disease an indication ${ }^{48,72,73}$ or possible indication for $\mathrm{IOL}^{42,51}$ without any further details provided. No guidelines comment on Rhesus disease.

\section{Fetal death}

In terms of fetal death, most guidelines state that IOL is recommended ${ }^{24,72-74}$, or that women should be offered the choice of IOL or expectant management $7,47,52,64$. Two guidelines state that vaginal birth is the recommended mode of birth for most women, but caesarean section will need to be considered in some cases ${ }^{47,58}$. Two guidelines stipulate that recommendations about labour and birth should take into account the woman's preferences and a process of shared decision-making should be used ${ }^{58,64}$.

\section{Discussion}

This review indicates some consistency as well as considerable variability across the guidelines. Indications where guidelines had mostly consistent advice included prolonged pregnancy (induction between 41 and 42 weeks), preterm premature rupture of membranes, and term preeclampsia (induction when preeclampsia diagnosed $\geq 37$ weeks). Guidelines were also consistent in agreeing on decreased fetal movements and oligohydramnios as valid indications for induction, although timing recommendations were absent or inconsistent. Common indications where there was little consensus on validity and/or timing of induction included gestational diabetes, fetal macrosomia, elevated maternal body mass index, and twin pregnancy. This variability does not appear reflective of variations in the quality of guidelines, as guidelines rated as similar in terms of quality also present conflicting recommendations. Similarly, recommendations from guidelines ranked as of low quality are often consistent with recommendations from high quality guidelines. 
More likely, the variability reflects the limited and conflicted evidence base in this space ${ }^{75,76}$. For some indications, there are very few or no high quality studies especially randomised controlled trials (RCTs) which often drive the recommendations in guidelines, with the literature largely consisting of case reports (e.g. alloimmune disease or Rhesus disease, antepartum haemorrhage, chorioamnionitis, heart disease) ${ }^{75-77}$. As such it is not surprising that for these indications guidelines provide unclear or conflicting recommendations. In relation to more common indications that have been studied more, there remains significant ambiguity in the literature and the tensions in the guidelines can be understood in terms of this complexity (see Table iii).

\section{Insert Table iii}

Table iii: Evidence supporting indications

\section{Prolonged pregnancy}

There remains uncertainty around the optimal timing of $\mathrm{IOL}^{78,79}$. As such the variations in guidelines in terms of the recommended timing of birth of for prolonged pregnancy is not unexpected.

\section{Premature Rupture of Membranes at term}

Evidence from a Cochrane review that included 23 RCTs indicates that planned early birth may help to reduce maternal and neonatal infection without increasing CS rates; however the quality of the evidence is low. As such, variation in guidelines are not unexpected.

\section{Twin pregnancies}

The existing evidence indicates that early planned birth for uncomplicated twin pregnancy does not improve outcomes ${ }^{80}$. In light of this, variations in terms of the recommended timing of IOL for twin pregnancy are not surprising.

\section{Intrahepatic cholestasis of pregnancy}

Evidence from one RCT indicates that early planned birth is not associated with improved outcomes, however this study was underpowered to detect clinically important differences ${ }^{81}$. Evidence from retrospective cohort studies suggests that planned early birth is associated with a significant reduction in the incidence of stillbirths, and that planned birth at 36 weeks gestation was associated with lower perinatal mortality ${ }^{82,83}$. Ambiguous and inconsistent guideline recommendations can be understood in light of this.

\section{Hypertension}

There is limited high quality evidence to inform decisions about optimal timing of birth ${ }^{84}$, with little to no agreement in the literature on timing of birth for women with chronic hypertension, gestational hypertension or mild preeclampsia at term ${ }^{75}$. Some evidence indicates that planned birth between 38 and 39 weeks balances the lowest maternal and neonatal morbidity/mortality for both women with gestational hypertension and those with chronic hypertension ${ }^{85,86}$. As such the variability in the guidelines in relation to timing, with some recommending $\mathrm{IOL}$ at 37 weeks and others recommending delaying IOL until 38 or 39 weeks can be understood in light of this literature. 
While there is a consensus in both the literature and across guidelines that women with onset of preeclampsia at $\geq 37$ weeks should be offered IOL, there is uncertainty around the management of preeclampsia with mild to moderate hypertension between 34 and 37 weeks ${ }^{75}$. The uncertainty in the literature is reflected in inconsistent recommendations across guidelines, with range from IOL at 34 to 37 weeks.

\section{Diabetes}

There is little quality evidence to inform management between IOL at term or expectant management, and the little evidence that is available is largely limited to gestational diabetes ${ }^{87,88}$. Again, this uncertainty in the literature is reflected in conflicting recommendations in guidelines.

Maternal elevated BMI

Evidence from retrospective cohort studies presents mixed findings. While some studies indicate that IOL is associated with reduced CS rates and improved maternal and neonatal outcomes ${ }^{89-91}$, other studies demonstrate the reverse ${ }^{92}$. Again, given this it is not unexpected that guidelines indicate IOL is appropriate while other guidelines do not.

\section{Maternal age,}

The conflicting recommendations in guidelines can be understood in light of the limited and conflicting evidence base. Evidence from one RCT indicates that IOL does not improve outcomes or $\mathrm{CS}$ rates for women greater than 35 years ${ }^{93}$. However this study was underpowered and contradicted by a retrospective cohort study that suggests that IOL at 40 weeks reduces perinatal mortality ${ }^{94}$.

\section{Suspected macrosomia,}

Evidence from four RCTs included in a Cochrane review indicates that there are no benefits associated with early $1 O L{ }^{95}$, however the included studies were underpowered and evidence from an observational study based on known birthweight suggests that IOL may reduce CS rates ${ }^{96}$. While most guidelines indicate $\mathrm{IOL}$ is not appropriate for suspected macrosomia, some guidelines indicate that it is appropriate in the context of 'known' birthweight following an ultrasound for estimated fetal weight.

\section{Suspected fetal compromise}

In the context of suspected fetal growth restriction, reduced fetal movements, oligohydramnios or fetal alloimmune disease or Rhesus disease, current studies are largely underpowered and there is significant uncertainty around when IOL is indicated and when birth can be delayed ${ }^{97,98}$. The somewhat vague recommendation in most guidelines that planned early birth is appropriate 'depending on clinical circumstances' can be understood in light of this.

As indicated in Table iii, the existing evidence base for most of the IOL indications is limited and

further high quality study designs, in particular RCTs, are required. Furthermore, given the complexity of the existing literature, and subsequent variability in recommendations in clinical guidelines, there is a need for more research into shared decision-making in a context of uncertainty. While much of the literature points to the importance of shared decision-making between consumers and practitioners, how shared decision-making is best performed in a context of medical uncertainty or ambiguity has not received much attention. There is an increasing 
recognition that practitioners are often not well equipped to tolerate ambiguity and engage consumers in shared decision-making in a context of uncertainty ${ }^{99}$. Our findings indicate significant variability in clinical guidelines in relation to indication and timing of IOL. While this can be largely understood in light of the existing evidence, this finding is also consistent with findings from other guideline reviews which highlight wide variability in guideline quality and recommendations, within maternity care $\mathrm{e}^{20,21,100}$ and other areas of healthcare ${ }^{101}$.

Rather than stipulating recommendations that are aligned with some of the evidence, but contradictory to other study findings, it may be more appropriate for guidelines to stress the importance of shared decision-making, and better support practitioners to engage in shared decision-making in a context of uncertainty and mixed study findings. Currently, only $20 \%$ of the included guidelines (10/49) mention that decisions should be informed by women's preferences and a process of shared decision-making $7,30,31,42,46,51,52,57,58,64$, and only four stipulate that if a woman chooses not to have IOL that her decision should be respected (mostly in the context of prolonged pregnancy) ${ }^{7,30,52,57}$. Furthermore, this review identified that some countries developed multiple guidelines, highlighting the health system structures in different countries (for example, a federated country like Australia can easily develop different guidelines in each state and territory as well as different professional groups). Rather than developing lots of different guidelines at a state or regional level, a focus on further improvement of national guidelines and then a push to preferential use of national guidelines may help improve practices around IOL.

The review provides an up to date assessment of IOL guidelines for all the common IOL indications, systematically analysed by two reviewers for both content and quality. Limitations include inclusion of English-language guidelines only, as there may have been additional valuable guidance and/or underlying contributing studies not published in English in the non-English language guidelines. We also may not have been able to access all relevant guidelines due to the online nature of data 
collection. The review is also of necessity limited by the quality and quantity of the underlying trials/original research that included guidelines draw upon: hence the necessity for further highquality IOL RCTs.

\section{Conclusion}

Substantial variation in clinical practice guidelines for common IOL indications exists, both within Australia and in other English-speaking high-income countries with broadly comparable healthcare systems. As guidelines rated of similar quality in this review presented conflicting recommendations, guideline variability was not explained by guideline quality. Rather, guideline variability appears to be reflecting differing, subjective interpretations of often sparse objective underlying evidence. This inconsistency underscores the difficulty of translating evidence into practice, and guideline variability may partly account for unexplained variation in IOL rates in different Australian settings. Implementation research into shared decision-making, as well as further high quality research to broaden the evidence base for contested IOL indications is recommended.

\section{Acknowledgements and Disclosures}

Funding for this study was received from Maridulu Budyari Gumal, the Sydney Partnership for Health, Education, Research and Enterprise (SPHERE). Caroline Homer is supported by a National Health and Medical Research Council (NHMRC) Research Fellowship. Amanda Henry is supported by a National Health and Medical Research Council (NHMRC) Early Career Fellowship.

\section{Conflict of Interest}


The Editor-in-Chief, Caroline Homer, played no role in the decision to peer review or ultimately accept this paper due to being a co-author. This was managed by the Deputy Editor Linda Sweet to avoid any perception or reality of conflict of interest. 
References (permission was received for more references than 40)

1. Centre for Epidemiology and Evidence. New South Wales Mothers and Babies 2016. Sydney: NSW Ministry of Health; 2017.

2. McCarthy F, Kenny L. Induction of labour. Obstetrics, Gynaecology and Reproductive Medicine 2013; 24(1): 9-15.

3. Zhang $X$, Kramer MS. The rise in singleton preterm births in the USA: the impact of labour induction. Bjog 2012; 119(11): 1309-15.

4. Humphrey $T$, Tucker JS. Rising rates of obstetric interventions: exploring the determinants of induction of labour. J Public Health (Oxf) 2009; 31(1): 88-94.

5. AlHW. Australia's mothers and babies 2016 - in brief. Canberra: Australian Institute of Health and Welfare; 2018.

6. AlHW. Australia's Health 2018, 2018.

7. NICE. Induction of labour: NICE clinical guideline 70. Manchester: NICE - National Institute for Health and Clinical Excellence; 2008.

8. Chang HH, Larson J, Blencowe $\mathrm{H}$. Preventing preterm births: analysis of trends and potential reductions with interventions in 39 countries with very high human development index. Lancet 2013; 381: 223-34.

9. AlHW. National core maternity indicators. Cat. no. PER 58. Canberra: National Perinatal Epidemiology and Statistics Unit 2013.

10. Nippita TA, Trevena JA, Patterson JA, Ford JB, Morris JM, Roberts CL. Inter-hospital variations in labor induction and outcomes for nullipara: a population-based linkage study. Acta Obstet Gynecol Scand 2016; 95.

11. Nippita TA, Trevena JA, Patterson JA, Ford JB, Morris JM, Roberts CL. Variation in hospital rates of induction of labour: a population-based record linkage study. BMJ Open 2015; 5.

12. Coulm B, Ray C, Lelong N, Drewniak N, Zeitlin J, Blondel B. Obstetric Interventions for LowRisk Pregnant Women in France: Do Maternity Unit Characteristics Make a Difference? Birth: Issues in Perinatal Care 2012; 39(3): 183-91.

13. Snyder CC, Wolfe KB, Loftin RW, et al. The influence of hospital type on induction of labor and mode of delivery. American Journal of Obstetrics \& Gynecology 2011; 205(4): 346.e1-4.

14. McCulloch P, Nagendran M, Campbell WB, Price A, Jani A, Birkmeyer JD. Strategies to reduce variation in the use of surgery. Lancet 2013; 382.

15. Wennberg JE. Forty years of unwarranted variation--and still counting. Health Policy 2014;

114.

16. Miller S, Abalos $\mathrm{E}$, Chamillard $\mathrm{M}$, et al. Beyond too little, too late and too much, too soon: a pathway towards evidence-based, respectful maternity care worldwide. The Lancet 2016;

388(10056): 2176-92.

17. Greenhalgh T. How to Implement Evidence-Based Healthcare. Oxford, UK: Wiley Blackwell; 2018.

18. Greenhalgh T, Howick J, Maskrey N. Evidence based medicine: a movement in crisis? BMJ 2014; 348.

19. Lemieux-Charles L, Palda VA, Brouwers MC, Gagliardi AR, Grimshaw JM. How can we improve guideline use? A conceptual framework of implementability. Implementation Science 2011; 6(1): 26.

20. Foureur M, Ryan CL, Nicholl M, Homer C. Inconsistent evidence: analysis of six national guidelines for vaginal birth after cesarean section. Birth 2010; 37(1): 3-10.

21. Homer CS, Scarf V, Catling C, Davis D. Culture-based versus risk-based screening for the prevention of group $B$ streptococcal disease in newborns: a review of national guidelines. Women Birth 2014; 27(1): 46-51.

22. Burgers J. Guideline quality and guideline content: are they related? . Clinical Chemistry 2006; 52(1): 3-4. 
23. AGREE Collaboration. Development and validation of an international appraisal instrument for assessing the quality of clinical practice guidelines: the AGREE project. Quality \& Safety in Health Care 2003; 12: 18-23.

24. WHO. WHO recommendations for Induction of labour: World Health Organisation; 2011.

25. ISSHP. The hypertensive disorders of pregnancy: ISSHP classification, diagnosis \& management recommendations for international practice. Australia: The International Society for the Study of Hypertension in Pregnancy (ISSHP); 2018.

26. Acuña-Izcaray A, Sánchez-Angarita E, Plaza V, et al. Quality Assessment of Asthma Clinical Practice Guidelines: A Systematic Appraisal. Chest 2013; 144(2): 390-7.

27. WHO. WHO handbook for guideline development. . Geneva: World Health Organization; 2012.

28. Yan J, Min J, Zhou B. Diagnosis of pheochromocytoma: a clinical practice guideline appraisal using AGREE II instrument. Journal of Evaluation in Clinical Practice 2013; 19: 626-32.

29. NSW Ministry of Health. Maternity - Management of Hypertensive disorders of pregnancy. Australia: NSW Ministry of Health; 2011.

30. NSW Ministry of Health. Maternity - Management of pregnancy beyond 41 weeks gestation. Australia: NSW Kids and Families, NSW Ministry of Health, NSW Health; 2014.

31. Department of Health. Clinical Practice Guidelines Pregnancy Care Australian Government Department of Health 2018.

32. PSANZ. Clinical Practice Guideline for the Care of Women with Decreased Fetal Movements. Australia Perinatal Society of Australia and New Zealand. Stillbirth and Neonatal Death Alliance; 2016.

33. King Edward Memorial Hospital. Clinical Guidelines: Complication of Pregnancy: Cholestasis in Pregnancy. Australia: King Edward Memorial Hospital: Women and Newborn Health Service. Government of Western Australia Department of Health; 2014.

34. King Edward Memorial Hospital. Clinical Practice Guideline: Hypertension in pregnancy: medical management. Australia: King Edward Memorial Hospital Obstetrics and Gynaecology. Government of Western Australia North Metropolitan Health Service Women and Newborn Health Service; 2015.

35. King Edward Memorial Hospital. Clinical Practice Guideline: Pregnancy Beyond 41 weeks: management of. Australia: King Edward Memorial Hospital Obstetrics and Gynaecology. Government of Western Australia North Metropolitan Health Service Women and Newborn Health Service; 2015.

36. King Edward Memorial Hospital. Clinical Practice Guideline: Pre-labour rupture of membranes at term. Australia: King Edward Memorial Hospital Obstetrics and Gynaecology. Government of Western Australia North Metropolitan Health Service Women and Newborn Health Service; 2016.

37. King Edward Memorial Hospital. Increased Body Mass Index: management of a woman with. Australia: King Edward Memorial Hospital Obstetrics and Gynaecology. Government of Western Australia North Metropolitan Health Service Women and Newborn Health Service; 2016.

38. King Edward Memorial Hospital. Small for Gestational Age and Intrauterine Growth Restriction: Management of Australia: Kind Edward Memorial Hospital Obstetrics and Gynaecology; 2016.

39. King Edward Memorial Hospital. Cardiac Disease. Australia: King Edward Memorial Hospital Obstetrics and Gynaecology. Government of Western Australia North Metropolitan Health Service Women and Newborn Health Service; 2018.

40. King Edward Memorial Hospital. Decreased Fetal Movements: Management of. Australia: King Edward Memorial Hospital Obstetrics and Gynaecology. Government of Western Australia North Metropolitan Health Service Women and Newborn Health Service; 2018.

41. King Edward Memorial Hospital. Diabetes in Pregnancy. Australia: King Edward Memorial Hospital Obstetrics and Gynaecology. Government of Western Australia North Metropolitan Health Service Women and Newborn Health Service; 2018. 
42. Queensland Health. Queensland Clinical Guidelines. Induction of Labour - Maternity and Neonatal Clinical Guideline. Australia: Queensland Health; 2017.

43. Queensland Health. Hypertensive disorders of pregnancy. Australia: Queensland Health; 2015.

44. Queensland Health. Obesity in pregnancy Australia: Queensland Health; 2015.

45. Queensland Health. Early Onset Group B Streptococcal disease. Australia: Queensland Health; 2017.

46. Queensland Health. Gestational diabetes mellitus Australia: Queensland Health; 2017.

47. Queensland Health. Stillbirth care. Australia: Queensland Health; 2018.

48. SA Maternal \& Neonatal Clinical Network. Clinical Guideline Induction of labour techniques. Australia: Government of South Australia; 2014.

49. SA Maternal \& Neonatal Clinical Network. Preterm Prelabour Rupture of the Membranes Australia: Government of South Australia; 2015.

50. SA Department of Health and Ageing. Cardiac disease in pregnancy: South Australian Perinatal Practice Guideline. Australia: Government of South Australia; 2018.

51. ACT Health. Canberra Hospital and Health Services Clinical Guideline: Induction of Labour. Canberra: ACT Government; 2018.

52. Victoria Health. Induction of Labour. 2018. https://www2.health.vic.gov.au/hospitals-andhealth-services/safer-care-victoria/maternity-ehandbook/induction-of-labour.

53. ADAU protocol group. Guideline for the management of oligohydramnious. UK: NHS Wales, University Health Board; 2015.

54. NICE. Hypertension in pregnancy: diagnosis and management. UK: National Institute for Health and Care Excellence (NICE) Guideline; 2010.

55. NICE. Multiple pregnancy: antenatal care for twin and triplet pregnancies. Clinical guideline [CG129]. 2011.

56. NICE. Diabetes in pregnancy: management from preconception to the postnatal period. UK: National Institute for Health and Care Excellence; 2015.

57. NICE. Antenatal care for uncomplicated pregnancies. UK: National Institute for Health and Care Excellence (NICE); 2008.

58. RCOG. Late Intrauterine Fetal Death and Stillbirth. UK: Royal College of Obstetricians \& Gynaecologists; 2010.

59. RCOG. Preterm Prelabour Rupture of Membranes UK: Royal College of Obstetricians \& Gynaecologists; 2010.

60. RCOG. Obstetric Cholestasis. UK: Royal College of Obstetricians \& Gynaecologists; 2011.

61. RCOG. Antepartum haemorrhage. London: Royal College of Obstetricians and Gynaecologists; 2011.

62. RCOG. Induction of Labour at Term in Older Mothers. Scientific Impact Paper No. 34. UK: Royal College of Obstetricians \& Gynaecologists; 2013.

63. RCOG. Management of Breech Presentations UK: Royal College of Obstetricians \& Gynaecologists; 2017.

64. Institute of Obstetricians and Gynaecologists. Investigation and management of late fetal intrauterine death and stillbirth. Ireland: Institute of Obstetricians \& Gynaecologists, Royal College of Physicians of Ireland and Directorate of Clinical Strategy and Programmes, Health Service Executive 2011.

65. Institute of Obstetricians \& Gynaecologists. Obesity and Pregnancy Clinical Practice Guideline. Ireland: Institute of Obstetricians \& Gynaecologists, Royal College of Physicians of Ireland and Clinical Strategy and Programmes Directorate, Health Service Executive 2011.

66. Institute of Obstetricians and Gynaecologists. Clinical practice guideline: management of multiple pregnancy. Ireland: Institute of Obstetricians and Gynaecologists, Royal College of Physicians of Ireland and Directorate of Strategy and Clinical Care, Health Service Executive 2012. 
67. Institute of Obstetricians and Gynaecologists. Preterm Prelabour Rupture of the Membranes. Ireland: Institute of Obstetricians and Gynaecologists, Royal College of Physicians of Ireland and Clinical Strategy and Programmes Division, Health Service Executive; 2013.

68. Institute of Obstetricians and Gynaecologists. The diagnosis and management of severe preeclampsia and eclampsia. Ireland: Institute of Obstetricians and Gynaecologists, Royal College of Physicians of Ireland and the Clinical Strategy and Programmes Division, Health Service Executive; 2016.

69. Institute of Obstetricians and Gynaecologists. The Management of Hypertension in Pregnancy. Clinical Practice Guideline. Ireland: Institute of Obstetricians and Gynaecologists, Royal College of Physicians of Ireland and Clinical Strategy and Programmes Division, Health Service Executive; 2016.

70. Institute of Obstetricians and Gynaecologists. Fetal-Growth-Restriction-RecognitionDiagnosis-and-Management. Ireland: Institute of Obstetricians and Gynaecologists, Royal College of Physicians of Ireland and Clinical Strategy and Programmes Division, Health Service Executive; 2017. 71. Institute of Obstetricians and Gynaecologists. The Management of Breech Presentation. National Clinical Guideline. Ireland: Institute of Obstetricians and Gynaecologists, Royal College of Physicians of Ireland and Clinical Strategy and Programmes Division, Health Service Executive; 2017. 72. ACOG. Induction of labor: ACOG practice bulletin. Clinical management guideline for obstretricians-gynecologists. America: The American College of Obstetricians and Gynaecologists 2009.

73. SOGC. SOGC Clinical Practice Guideline, Induction of Labour Canada: Society of Obstetricians and Gynaecologists of Canada; 2013.

74. National Women's Health. Induction of Labour. New Zealand: Auckland District Health Board; 2015.

75. Coates D, Henry A, Makris A, et al. A systematic scoping review of clinical indications for induction of labour: Fetal conditions including post-term pregnancy (Part 2). Obstet Gynecol under review.

76. Mozurkewich EL, Chilimigras JL, Koepke E, Keeton KL, King V. Indications for induction of labour: a best-evidence review. BJOG 2009; 116: 626-36.

77. Coates D, Makris A, Catling C, et al. A systematic scoping review of clinical indications for induction of labour: Maternal conditions and general pregnancy conditions (Part 1). Obstet Gynecol under review.

78. Middleton $\mathrm{P}$, Shepherd $\mathrm{E}$, Crowther $\mathrm{C}$. Induction of labour for improving birth outcomes for women at or beyond term. Cochrane Database Syst Rev 2018; Rev 5. CD004945.

79. Keulen JKJ, Bruinsma A, Kortekaas JC, van Dillen J, van der Post JAM, de Miranda E. Timing induction of labour at 41 or 42 weeks? A closer look at time frames of comparison: A review. Midwifery 2018; 66: 111-8.

80. Dodd J, Deussen AR, Grivell RM, Crowther CA. Elective birth at 37 weeks' gestation for women with an uncomplicated twin pregnancy. Cochrane Database Syst Rev 2014; (2): Cd003582.

81. Gurung V, Stokes M, Middleton P, Milan SJ, Hague W, Thornton JG. Interventions for treating cholestasis in pregnancy. Cochrane Database of Systematic Reviews 2013; (6).

82. Kohari KS, Carroll R, Capogna S, Ditchik A, Fox NS, Ferrara LA. Outcome after implementation of a modern management strategy for intrahepatic cholestasis of pregnancy. The Journal of Maternal-Fetal \& Neonatal Medicine 2017; 30(11): 1342-6.

83. Puljic A, Kim E, Page J, et al. The risk of infant and fetal death by each additional week of expectant management in intrahepatic cholestasis of pregnancy by gestational age. American Journal of Obstetrics and Gynecology 2015; 212(5): 667.e1-.e5.

84. Cluver C, Novikova N, Koopmans CM, West HM. Planned early delivery versus expectant management for hypertensive disorders from 34 weeks gestation to term. Cochrane Database Syst Rev 2017; 1: Cd009273. 
85. Cruz MO, Gao W, Hibbard JU, Cruz MO, Gao W, Hibbard JU. What is the optimal time for delivery in women with gestational hypertension? American Journal of Obstetrics \& Gynecology 2012; 207(3): 214.e1-6.

86. Hutcheon J, Lisonkova S, Magee L, et al. Optimal timing of delivery in pregnancies with preexisting hypertension. Pregnancy hypertension 2010; 1 ): S34.

87. Boulvain M, Stan CM, Irion O. Elective delivery in diabetic pregnant women. Cochrane Database of Systematic Reviews 2009; (4) (no pagination)(CD001997).

88. Biesty LM, Egan AM, Dunne F, et al. Planned birth at or near term for improving health outcomes for pregnant women with pre-existing diabetes and their infants. Cochrane Database Syst Rev 2018; 2: Cd012948.

89. Kawakita T, Iqbal SN, Huang C-C, Reddy UM. Nonmedically indicated induction in morbidly obese women is not associated with an increased risk of cesarean delivery. American Journal of Obstetrics \& Gynecology 2017; 217(4): 451.e1-.e8.

90. Pickens CMG, Kramer MR, Howards PP, et al. Term Elective Induction of Labor and Pregnancy Outcomes Among Obese Women and Their Offspring. Obstetrics \& Gynecology 2018; 131(1): 12-22.

91. Lee V, Darney B, Snowden J, et al. Term elective induction of labour and perinatal outcomes in obese women: retrospective cohort study. BJOG: An International Journal of Obstetrics \& Gynaecology 2016; 123(2): 271-8.

92. Wolfe H, Timofeev J, Tefera E, Desale S, Driggers RW. Risk of cesarean in obese nulliparous women with unfavorable cervix: elective induction vs expectant management at term. American Journal of Obstetrics \& Gynecology 2014; 211(1): 53.e1-5.

93. Walker KF, Malin G, Wilson P, Thornton JG. Induction of labour versus expectant management at term by subgroups of maternal age: an individual patient data meta-analysis. European journal of obstetrics, gynecology, and reproductive biology 2016; 197: 1-5.

94. Knight HE, Cromwell DA, Gurol-Urganci I, Harron K, van der Meulen JH, Smith GCS. Perinatal mortality associated with induction of labour versus expectant management in nulliparous women aged 35 years or over: An English national cohort study. PLoS Med 2017; 14(11): e1002425.

95. Boulvain M, Irion O, Dowswell T, Thornton JG. Induction of labour at or near term for suspected fetal macrosomia. Cochrane Database Syst Rev 2016; (5): Cd000938.

96. Cheng YW, Sparks TN, Laros RK, et al. Impending macrosomia: will induction of labour modify the risk of caesarean delivery? BJOG: An International Journal of Obstetrics and Gynaecology 2012; 119(4): 402-9.

97. Stock SJ, Bricker L, Norman JE, West HM. Immediate versus deferred delivery of the preterm baby with suspected fetal compromise for improving outcomes. Cochrane Database Syst Rev 2016; 7: Cd008968.

98. Bond DM, Gordon A, Hyett J, de Vries B, Carberry AE, Morris J. Planned early delivery versus expectant management of the term suspected compromised baby for improving outcomes. Cochrane Database Syst Rev 2015; (11): Cd009433.

99. Domen RE. The Ethics of Ambiguity:Rethinking the Role and Importance of Uncertainty in Medical Education and Practice. Academic Pathology 2016; 3: 2374289516654712.

100. Greuter M, van Emmerik N, Wouters M, van Tulder M. Quality of guidelines on the management of diabetes in pregnancy: a systematic review. . BMC Pregnancy and Childbirth 2012; 12(58).

101. Yang C, Zhang Z, Zhang L, et al. Quality assessment of clinical practice guidelines on tic disorders with AGREE II instrument. Psychiatry Research 2018; 259: 385-91. 
Table i: IOL Indications

\begin{tabular}{|c|c|c|c|c|c|c|c|c|c|c|c|c|c|c|c|c|c|c|c|c|c|c|c|c|}
\hline 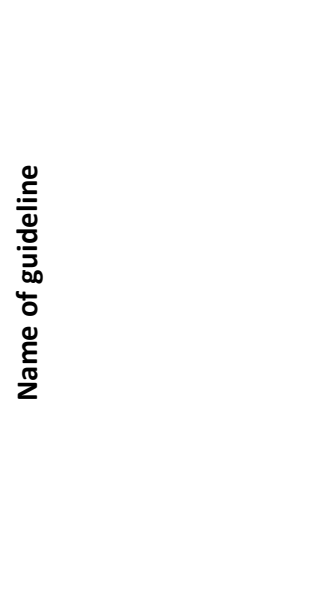 &  & 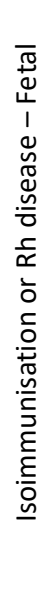 & 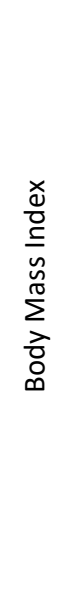 & 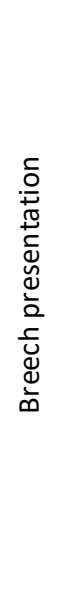 & 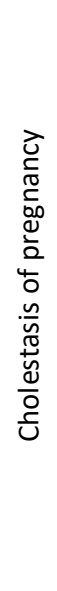 & 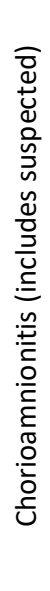 &  & 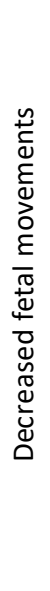 & 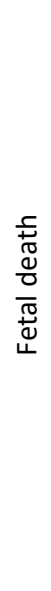 & 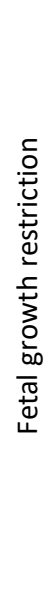 & 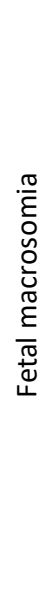 & 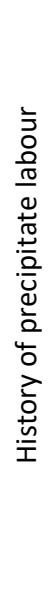 &  & 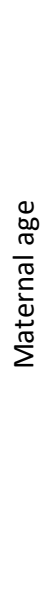 & 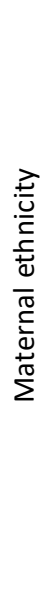 &  & 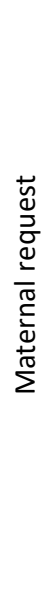 & 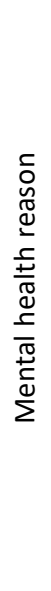 & 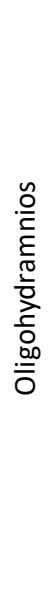 & 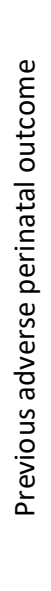 & 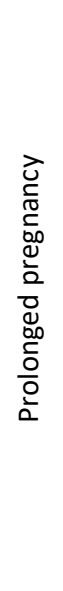 & 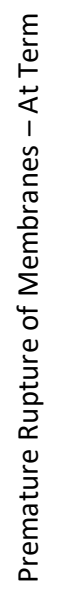 & 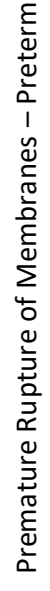 & 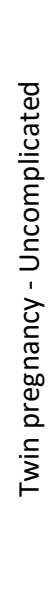 \\
\hline $\begin{array}{l}\text { Department of Health }{ }^{31} \\
(2018)^{\ddagger}\end{array}$ & & & & & & & & & & & & & & & & & & & & & $\begin{array}{l}\text { Y } \\
\text { WC }\end{array}$ & & & \\
\hline PSANZ $^{32}(2016)^{\ddagger}$ & & & & & & & & $M$ & & & & & & & & & & & & & & & & \\
\hline $\begin{array}{l}\text { King Edward Memorial } \\
\text { Hospital }^{33}(2014)^{\ddagger}\end{array}$ & & & & & $Y$ & & & & & & & & & & & & & & & & & & & \\
\hline $\begin{array}{l}\text { King Edward Memorial } \\
\text { Hospital }^{34}(2015)^{\ddagger}\end{array}$ & & & & & & & & & & & & & $Y$ & & & & & & & & & & & \\
\hline $\begin{array}{l}\text { King Edward Memorial } \\
\text { Hospital }{ }^{35}(2015)^{\ddagger}\end{array}$ & & & & & & & & & & & & & & & & & & & & & $Y$ & & & \\
\hline $\begin{array}{l}\text { King Edward Memorial } \\
\text { Hospital }^{36}(2016)^{\ddagger}\end{array}$ & & & & & & & & & & & & & & & & & & & & & & $Y$ & & \\
\hline $\begin{array}{l}\text { King Edward Memorial } \\
\text { Hospital }^{37}(2016)^{\ddagger}\end{array}$ & & & $\mathrm{N}$ & & & & & & & & & & & & & & & & & & & & & \\
\hline $\begin{array}{l}\text { King Edward Memorial } \\
\text { Hospital }^{38}(2016)^{\ddagger}\end{array}$ & & & & & & & & & & $Y$ & & & & & & & & & & & & & & \\
\hline $\begin{array}{l}\text { King Edward Memorial } \\
\text { Hospital }{ }^{39}(2018)^{\ddagger}\end{array}$ & & & & & & & & & & & & & & & & $M$ & & & & & & & & \\
\hline
\end{tabular}




\begin{tabular}{|c|c|c|c|c|c|c|c|c|c|c|c|c|c|c|c|c|c|c|c|c|c|c|c|}
\hline $\begin{array}{l}\text { King Edward Memorial } \\
\text { Hospital }{ }^{40}(2018)^{\ddagger}\end{array}$ & & & & & & & & $M$ & & & & & & & & & & & & & & & \\
\hline $\begin{array}{l}\text { King Edward Memorial } \\
\text { Hospital }{ }^{41}(2018)^{\ddagger}\end{array}$ & & & & & & & $M$ & & & & & & & & & & & & & & & & \\
\hline $\begin{array}{l}\text { Queensland Health }{ }^{42} \\
(2017)^{+}\end{array}$ & & $M$ & & & $M$ & & $M$ & $M$ & & $\mathrm{M}$ & $M$ & & & $\mathrm{Y}$ & $\mathrm{N}$ & & $M$ & & $M$ & $\begin{array}{l}Y \\
W C \\
\end{array}$ & & & $Y$ \\
\hline $\begin{array}{l}\text { Queensland Health }{ }^{43} \\
(2015)^{\ddagger}\end{array}$ & & & & & & & & & & & & & $\mathrm{Y}$ & & & & & & & & & & \\
\hline $\begin{array}{l}\text { Queensland Health }{ }^{44} \\
(2015)^{\ddagger}\end{array}$ & & & $M$ & & & & & & & & & & & & & & & & & & & & \\
\hline $\begin{array}{l}\text { Queensland Health }{ }^{45} \\
(2017)^{\ddagger}\end{array}$ & & & & & & $Y$ & & & & & & & & & & & & & & & $\begin{array}{l}M \\
W C\end{array}$ & & \\
\hline $\begin{array}{l}\text { Queensland Health }{ }^{46} \\
(2017)^{\ddagger}\end{array}$ & & & & & & & $\begin{array}{l}\mathrm{M} \\
\mathrm{WC}\end{array}$ & & & & & & & & & & & & & & & & \\
\hline $\begin{array}{l}\text { Queensland Health }{ }^{47} \\
(2018)^{\ddagger}\end{array}$ & & & & & & & & & WC & & & & & & & & & & & & & & \\
\hline $\begin{array}{l}\text { NSW Ministry of Health }{ }^{29} \\
(2011)^{\ddagger}\end{array}$ & & & & & & & & & & & & & $\mathrm{Y}$ & & & & & & & & & & \\
\hline $\begin{array}{l}\text { NSW Ministry of Health }{ }^{30} \\
(2014)^{\ddagger}\end{array}$ & & & & & & & & & & & & & & & & & & & & $\begin{array}{l}Y \\
W C\end{array}$ & & & \\
\hline $\begin{array}{l}\text { SA Maternal \& Neonatal } \\
\text { Clinical Network }{ }^{48}(2014)^{+}\end{array}$ & & $\mathrm{Y}$ & & & & & $\mathrm{Y}$ & & & $\mathrm{Y}$ & & & $\mathrm{Y}$ & & & & & & $M$ & $\mathrm{Y}$ & & & \\
\hline $\begin{array}{l}\text { SA Maternal \& Neonatal } \\
\text { Clinical Network } 49(2015)^{\ddagger}\end{array}$ & & & & & & & & & & & & & & & & & & & & & & $M$ & \\
\hline $\begin{array}{l}\text { SA Department of Health } \\
\text { and Ageing }{ }^{50}(2018)^{\ddagger}\end{array}$ & & & & & & & & & & & & & & & & $M$ & & & & & & & \\
\hline Victoria Health $^{52}(2018)^{\dagger}$ & $M$ & & $Y$ & $\begin{array}{l}\text { WC } \\
M\end{array}$ & & & $M$ & $M$ & WC & $\mathrm{Y}$ & $\mathrm{N}$ & $\mathrm{N}$ & $Y$ & $\mathrm{~N}$ & $\mathrm{~N}$ & & $M$ & $M$ & & $\begin{array}{l}Y \\
W C\end{array}$ & $Y$ & $M$ & \\
\hline ACT Health ${ }^{51}(2018)^{\dagger}$ & & $M$ & & & $M$ & & $M$ & $M$ & & $\mathrm{M}$ & $M$ & & & $Y$ & $\mathrm{~N}$ & & $M$ & & $M$ & $\begin{array}{l}\text { Y } \\
\text { WC }\end{array}$ & & & $Y$ \\
\hline $\begin{array}{l}\text { ADAU protocol group }{ }^{53} \\
(2015)^{\ddagger}\end{array}$ & & & & & & & & & & & & & & & & & & & $M$ & & & & \\
\hline $\operatorname{NICE}^{57}(2008)^{\ddagger}$ & & & & & & & & & & & & & & & & & & & & $\begin{array}{l}Y \\
W C\end{array}$ & & & \\
\hline $\operatorname{NICE}^{7}(2008)^{\dagger}$ & & & & $\begin{array}{l}\mathrm{N} \\
\mathrm{WC}\end{array}$ & & & & & WC & $M$ & $\mathrm{~N}$ & $N$ & & & & & $M$ & & & $\begin{array}{l}Y \\
W C\end{array}$ & WC & M & \\
\hline $\operatorname{NICE}^{54}(2010)^{\ddagger}$ & & & & & & & & & & & & & $\begin{array}{l}\mathrm{Y} \\
\mathrm{WC}\end{array}$ & & & & & & & & & & \\
\hline
\end{tabular}




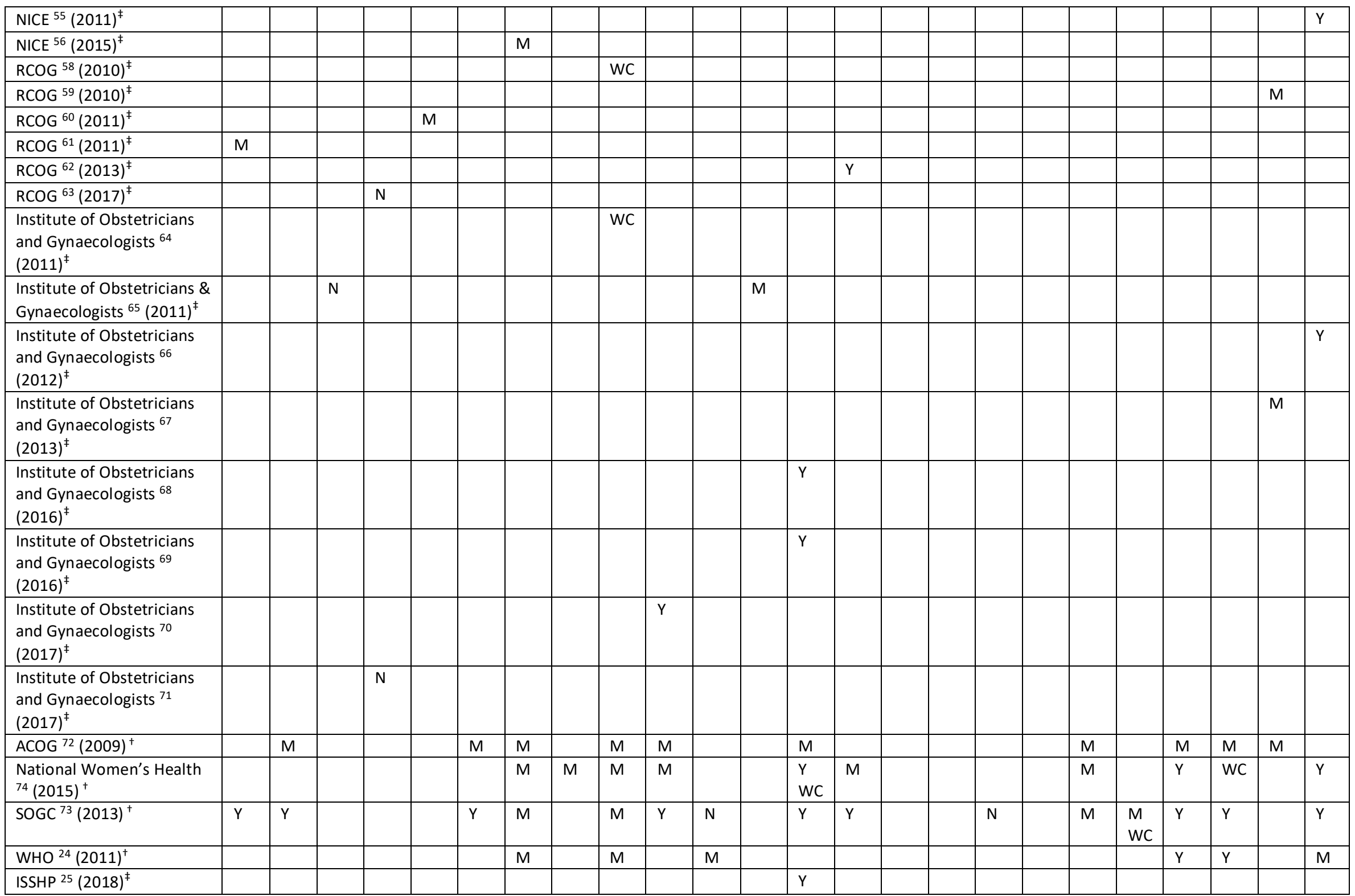


*Not relevant to high risk pregnancies and only covers prolonged pregnancy

† IOL guidelines; ¥Guidelines about specific indicators; ¥ Maternity care guidelines

WC= Woman's Choice; $M=$ Maybe; $Y=y e s ; N=N o ; B l a n k-$ not mentioned

\section{Table ii: AGREE Scores}






\begin{tabular}{|c|c|c|c|c|c|c|c|c|c|}
\hline Queensland Health ${ }^{43}(2015)^{\ddagger}$ & Hypertensive disorders of pregnancy & Australia, QLD & 95 & 61 & 52 & 76 & 71 & 64 & $\begin{array}{l}\text { 6; highly } \\
\text { recommended }\end{array}$ \\
\hline Queensland Health ${ }^{44}(2015)^{\ddagger}$ & Obesity in pregnancy & Australia & 86 & 74 & 56 & 86 & 61 & 78 & $\begin{array}{l}6 \text {; highly } \\
\text { recommended }\end{array}$ \\
\hline Queensland Health $^{45}(2017)^{\ddagger}$ & Early Onset Group B Streptococcal disease & Australia & 92 & 71 & 55 & 71 & 77 & 64 & $\begin{array}{l}6 \text {; highly } \\
\text { recommended }\end{array}$ \\
\hline Queensland Health ${ }^{46}(2017)^{\ddagger}$ & Gestational diabetes mellitus 2017 & Australia & 88 & 69 & 53 & 78 & 71 & 78 & $\begin{array}{l}\text { 6; highly } \\
\text { recommended }\end{array}$ \\
\hline Queensland Health ${ }^{47}(2018)^{\ddagger}$ & Stillbirth care & Australia & 88 & 74 & 51 & 81 & 55 & 75 & $\begin{array}{l}6 \text {; highly } \\
\text { recommended }\end{array}$ \\
\hline $\begin{array}{l}\text { NSW Ministry of Health }{ }^{29} \\
(2011)^{\ddagger}\end{array}$ & $\begin{array}{l}\text { Management of hypertensive disorders of } \\
\text { pregnancy }\end{array}$ & $\begin{array}{l}\text { Australia, } \\
\text { NSW }\end{array}$ & 90 & 45 & 38 & 51 & 45 & 28 & $\begin{array}{l}4 ; \text { recommended } \\
\text { with provisions or } \\
\text { alterations }\end{array}$ \\
\hline $\begin{array}{l}\text { NSW Ministry of Health }{ }^{30} \\
(2014)^{\ddagger}\end{array}$ & $\begin{array}{l}\text { Management of pregnancy beyond } 41 \\
\text { weeks gestation }\end{array}$ & $\begin{array}{l}\text { Australia, } \\
\text { NSW }\end{array}$ & 88 & 38 & 38 & 73 & 23 & 14 & $\begin{array}{l}\text { 3; recommended } \\
\text { with provisions or } \\
\text { alterations }\end{array}$ \\
\hline $\begin{array}{l}\text { SA Maternal \& Neonatal } \\
\text { Clinical Network }^{48}(2014)^{+}\end{array}$ & Induction of labour techniques & Australia, SA & 62 & 45 & 37 & 57 & 17 & 14 & $\begin{array}{l}3 \text {; recommended } \\
\text { with provisions or } \\
\text { alterations }\end{array}$ \\
\hline $\begin{array}{l}\text { SA Maternal \& Neonatal } \\
\text { Clinical Network }{ }^{49}(2015)^{\ddagger}\end{array}$ & $\begin{array}{l}\text { Preterm Prelabour Rupture of the } \\
\text { Membranes }\end{array}$ & Australia, SA & 50 & 31 & 29 & 59 & 19 & 14 & $\begin{array}{l}3 ; \text { not } \\
\text { recommended }\end{array}$ \\
\hline $\begin{array}{l}\text { SA Department of Health and } \\
\text { Ageing }{ }^{50}(2018)^{\ddagger}\end{array}$ & Cardiac disease in pregnancy & Australia, SA & 73 & 31 & 23 & 57 & 17 & 14 & $\begin{array}{l}\text { 3.5; recommended } \\
\text { with provisions or } \\
\text { alterations }\end{array}$ \\
\hline Victoria Health $^{52}(2018)^{+}$ & Induction of Labour & $\begin{array}{l}\text { Australia, } \\
\text { Victoria }\end{array}$ & 33 & 16 & 25 & 66 & 43 & 14 & $\begin{array}{l}\text { 3.5; recommended } \\
\text { with provisions or } \\
\text { alterations }\end{array}$ \\
\hline ACT Health ${ }^{51}(2018)^{\dagger}$ & Induction of Labour & Australia, ACT & 64 & 59 & 31 & 83 & 19 & 14 & $\begin{array}{l}\text { 3.5; recommended } \\
\text { with provisions or } \\
\text { alterations }\end{array}$ \\
\hline ADAU protocol group ${ }^{53}(2015)^{\ddagger}$ & $\begin{array}{l}\text { Guideline for the management of } \\
\text { oligohydramnios }\end{array}$ & UK & 43 & 21 & 19 & 43 & 25 & 14 & $\begin{array}{l}2.5 ; \text { not } \\
\text { recommended }\end{array}$ \\
\hline $\operatorname{NICE}^{57}(2008)^{\ddagger}$ & $\begin{array}{l}\text { Antenatal care for uncomplicated } \\
\text { pregnancies }\end{array}$ & UK & 85 & 78 & 46 & 81 & 34 & 21 & $\begin{array}{l}4.5 \text {; recommended } \\
\text { with provisions or } \\
\text { alterations }\end{array}$ \\
\hline $\operatorname{NICE}^{7}(2008)^{+}$ & Induction of labour: NICE clinical guideline & UK & 76 & 71 & 85 & 78 & 30 & 21 & $\begin{array}{l}\text { 6; highly } \\
\text { recommended }\end{array}$ \\
\hline $\operatorname{NICE}^{54}(2010)^{\ddagger}$ & $\begin{array}{l}\text { Hypertension in pregnancy: diagnosis and } \\
\text { management }\end{array}$ & UK & 90 & 97 & 85 & 93 & 47 & 17 & $\begin{array}{l}5 \text {; highly } \\
\text { recommended }\end{array}$ \\
\hline
\end{tabular}




\begin{tabular}{|c|c|c|c|c|c|c|c|c|c|}
\hline $\operatorname{NICE}^{55}(2011)^{\ddagger}$ & $\begin{array}{l}\text { Multiple pregnancy: antenatal care for twin } \\
\text { and triplet pregnancies }\end{array}$ & UK & 90 & 76 & 80 & 81 & 30 & 36 & $\begin{array}{l}\text { 5.5; highly } \\
\text { recommended }\end{array}$ \\
\hline $\operatorname{NICE}^{56}(2015)^{\ddagger}$ & $\begin{array}{l}\text { Diabetes in pregnancy: management from } \\
\text { preconception to the postnatal period }\end{array}$ & UK & 100 & 92 & 82 & 95 & 84 & 68 & $\begin{array}{l}\text { 6; highly } \\
\text { recommended }\end{array}$ \\
\hline RCOG $^{58}(2010)^{\ddagger}$ & Late Intrauterine Fetal Death and Stillbirth & UK & 97 & 83 & 97 & 91 & 66 & 14 & $\begin{array}{l}\text { 6; highly } \\
\text { recommended }\end{array}$ \\
\hline $\operatorname{RCOG}^{59}(2010)^{\ddagger}$ & Preterm Prelabour Rupture of Membranes & UK & 95 & 71 & 79 & 76 & 43 & 21 & $\begin{array}{l}\text { 6; highly } \\
\text { recommended }\end{array}$ \\
\hline $\operatorname{RCOG}^{60}(2011)^{\ddagger}$ & Obstetric Cholestasis & UK & 83 & 57 & 94 & 81 & 52 & 14 & $\begin{array}{l}5 ; \text { recommended } \\
\text { with provisions or } \\
\text { alterations }\end{array}$ \\
\hline $\operatorname{RCOG}^{61}(2011)^{\ddagger}$ & Antepartum haemorrhage & UK & 71 & 62 & 82 & 83 & 31 & 17 & $\begin{array}{l}4.5 \text {; recommended } \\
\text { with provisions or } \\
\text { alterations }\end{array}$ \\
\hline $\operatorname{RCOG}^{62}(2013)^{\ddagger}$ & $\begin{array}{l}\text { Induction of Labour at Term in Older } \\
\text { Mothers }\end{array}$ & UK & 52 & 40 & 42 & 24 & 14 & 14 & $\begin{array}{l}\text { 3; recommended } \\
\text { with provisions or } \\
\text { alterations }\end{array}$ \\
\hline $\operatorname{RCOG}^{63}(2017)^{\ddagger}$ & Management of Breech Presentations & UK & 86 & 57 & 88 & 97 & 51 & 57 & $\begin{array}{l}5 \text {; recommended } \\
\text { with provisions or } \\
\text { alterations }\end{array}$ \\
\hline $\begin{array}{l}\text { Institute of Obstetricians and } \\
\text { Gynaecologists }{ }^{64}(2011)^{\ddagger}\end{array}$ & $\begin{array}{l}\text { Investigation and management of late fetal } \\
\text { intrauterine death and stillbirth }\end{array}$ & Ireland & 88 & 45 & 61 & 88 & 62 & 14 & $\begin{array}{l}4.5 ; \text { highly } \\
\text { recommended }\end{array}$ \\
\hline $\begin{array}{l}\text { Institute of Obstetricians \& } \\
\text { Gynaecologists }{ }^{65}(2011)^{\ddagger}\end{array}$ & $\begin{array}{l}\text { Obesity and Pregnancy Clinical Practice } \\
\text { Guideline }\end{array}$ & Ireland & 71 & 57 & 61 & 83 & 41 & 14 & $\begin{array}{l}3.5 \text {; recommended } \\
\text { with provisions or } \\
\text { alterations }\end{array}$ \\
\hline $\begin{array}{l}\text { Institute of Obstetricians and } \\
\text { Gynaecologists }{ }^{66}(2012)^{\ddagger}\end{array}$ & Management of multiple pregnancy & Ireland & 76 & 57 & 61 & 83 & 30 & 25 & $\begin{array}{l}4 ; \text { recommended } \\
\text { with provisions or } \\
\text { alterations }\end{array}$ \\
\hline $\begin{array}{l}\text { Institute of Obstetricians and } \\
\text { Gynaecologists }{ }^{67}(2013)^{\ddagger}\end{array}$ & $\begin{array}{l}\text { Preterm Prelabour Rupture of the } \\
\text { Membranes }\end{array}$ & Ireland & 42 & 38 & 29 & 43 & 14 & 14 & $\begin{array}{l}2.5 \text {; recommended } \\
\text { with provisions or } \\
\text { alterations }\end{array}$ \\
\hline $\begin{array}{l}\text { Institute of Obstetricians and } \\
\text { Gynaecologists }{ }^{68}(2016)^{\ddagger}\end{array}$ & $\begin{array}{l}\text { The diagnosis and management of severe } \\
\text { pre-eclampsia and eclampsia }\end{array}$ & Ireland & 83 & 66 & 55 & 81 & 46.5 & 14 & $\begin{array}{l}3.5 \text {; recommended } \\
\text { with provisions or } \\
\text { alterations }\end{array}$ \\
\hline $\begin{array}{l}\text { Institute of Obstetricians and } \\
\text { Gynaecologists }{ }^{69}(2016)^{\ddagger}\end{array}$ & $\begin{array}{l}\text { The Management of Hypertension in } \\
\text { Pregnancy }\end{array}$ & Ireland & 88 & 64 & 35 & 52 & 32 & 14 & $\begin{array}{l}3.5 \text {; recommended } \\
\text { with provisions or } \\
\text { alterations }\end{array}$ \\
\hline $\begin{array}{l}\text { Institute of Obstetricians and } \\
\text { Gynaecologists }{ }^{70}(2017)^{\ddagger}\end{array}$ & $\begin{array}{l}\text { Fetal-Growth-Restriction-Recognition- } \\
\text { Diagnosis-and-Management }\end{array}$ & Ireland & 76 & 57 & 38 & 45 & 28 & 14 & $\begin{array}{l}\text { 3; recommended } \\
\text { with provisions or } \\
\text { alterations }\end{array}$ \\
\hline
\end{tabular}




\begin{tabular}{|c|c|c|c|c|c|c|c|c|c|}
\hline $\begin{array}{l}\text { Institute of Obstetricians and } \\
\text { Gynaecologists }{ }^{71}(2017)^{\ddagger}\end{array}$ & The Management of Breech Presentation & Ireland & 90 & 64 & 38 & 64 & 26 & 28 & $\begin{array}{l}4 \text {; recommended } \\
\text { with provisions or } \\
\text { alterations }\end{array}$ \\
\hline $\operatorname{ACOG}^{72}(2009)^{+}$ & Induction of Labor & USA & 71 & 26 & 33 & 57 & 19 & 14 & $\begin{array}{l}\text { 3.5; recommended } \\
\text { with provisions or } \\
\text { alterations }\end{array}$ \\
\hline $\begin{array}{l}\text { National Women's Health }{ }^{74} \\
(2015)^{+}\end{array}$ & Induction of Labour & New Zealand & 71 & 38 & 29 & 71 & 18 & 14 & $\begin{array}{l}\text { 3; recommended } \\
\text { with provisions or } \\
\text { alterations }\end{array}$ \\
\hline $\operatorname{SOGC}^{73}(2013)^{+}$ & Induction of Labour & Canada & 43 & 57 & 62 & 88 & 28 & 57 & $\begin{array}{l}\text { 3.5; recommended } \\
\text { with provisions or } \\
\text { alterations }\end{array}$ \\
\hline $\mathrm{WHO}^{24}(2011)^{\dagger}$ & $\begin{array}{l}\text { WHO recommendations for Induction of } \\
\text { labour }\end{array}$ & International & 90 & 66 & 85 & 93 & 84 & 60 & $\begin{array}{l}\text { 6; highly } \\
\text { recommended }\end{array}$ \\
\hline ISSHP $25(2018)^{\ddagger}$ & $\begin{array}{l}\text { The hypertensive disorders of pregnancy: } \\
\text { ISSHP classification, diagnosis \& } \\
\text { management recommendations for } \\
\text { international practice }\end{array}$ & International & 81 & 62 & 70 & 66 & 41 & 100 & $\begin{array}{l}5 \text {; highly } \\
\text { recommended }\end{array}$ \\
\hline
\end{tabular}

$\dagger$ IOL guidelines; $¥$ Guidelines about specific indicators; $¥$ Maternity care guidelines

ACT=Australian Capital Territory; NSW= New South Wales; $S A=$ South Australia; WA=Western Australia; QLD=Queensland 